\title{
CIRCUITO ESPACIAL DE PRODUÇÃO E LUGAR
}

Aldo Dantas ${ }^{1}$

\begin{abstract}
Resumo
O presente ensaio tem por objetivo frisar a necessidade de se levar em consideração a categoria lugar ao se fazer a análise de um fenômeno econômico tomando-se por base o conceito de circuito espacial de produção. Tomando com pressuposto a ideia de que somente podemos falar em circuito espacial a partir da mobilidade e suas duas faces: a circulação e a comunicação, o texto passa a analisar os fluxos matérias e imateriais levando em consideração a base material que dá sustentação a tais fluxos. Essa base material permite se falar em configuração territorial e singularidade dos lugares, o que nos remete ao que Milton Santas chama de lei do lugar.
\end{abstract}

Palavras-chaves: Circuito espacial de produção; Lugar; mobilidade.

\section{SPATIAL PRODUCTION CIRCUIT AND PLACE}

\begin{abstract}
The paper aims at highlighting the need of taking into account the place category when analyzing an economical phenomenon based on the concept of spatial production circuit. Assuming that we can only mention spatial circuit starting from mobility and its two features - circulation and communication -, the text analyzes both material and immaterial flows considering the material baseline that sustains these flows. Such a material basis allows us to talk about territorial configuration and place singularity, referring to what Milton Santos calls place's law.
\end{abstract}

Key-words: spatial production circuit, place, mobility

\section{CIRCUITO DEL ESPACIO DE LA PRODUCCIÓN Y LUGAR}

\section{Resumen}

El artículo tiene como objetivo discutir la necesidad de se considerar la categoría lugar en las análisis del fenómeno económico con base en el concepto de circuito del espacio de la producción. Suponiendo que sólo podemos hablar del circuito del espacio teniendo en cuenta la movilidad y sus dos facetas - la circulación y la comunicación - , el texto pasa a analizar los flujos materialies y inmateriales teniendo en cuenta la base material que soporte a los flujos. Esta base material nos permite hablar de la configuración territorial y la singularidad de los lugares, que se refiere a lo que Milton Santos llama la ley del lugar .

Palabras clave: Circuitos de los espacios de la producción, lugar, movilidad.

\footnotetext{
${ }^{1}$ Doutor em Geografia pela Universidade de São Paulo (USP), Professor do Departamento de Geografia (DGE) e do Programa de Pós-Graduação e Pesquisa em Geografia (PPGE) da Universidade Federal do Rio Grande do Norte (UFRN). Email: aldodantasufrn@gmail.com
} 
Nosso objetivo neste texto é tão somente chamar a atenção para a importância da categoria lugar na compreensão dos circuitos espaciais de produção e dos círculos de cooperação. Recomendamos, portanto que seja complementado com a leitura da bibliografia citada.

O que nos autoriza, o que nos dá fundamento para falar em circuito espacial na geografia é a mobilidade, que tem na circulação e na comunicação as suas duas faces indissociáveis. Essas duas faces nos permitem analisar os fluxos materiais e imateriais de qualquer ordem. No caso em tela e considerando a sociedade em que vivemos é pertinente falarmos em circuito espacial produtivo.

Como nos chama atenção Castillo e Frederico (2010), uma das marcas do nosso período é o crescimento dos fluxos relacionados à mundialização da produção. A base material que viabiliza esse crescimento é o desenvolvimento dos sistemas de engenharia relacionados às telecomunicações e aos transportes, o que nos remete mais uma vez à ideia de mobilidade, circulação e comunicação.

Quando falamos em mobilidade estamos nos referindo a um conjunto que envolve valores, regras, condições geográficas (aqui compreendido os dispositivos tecnológicos), econômicas e sociais, ou seja, um conjunto que possibilita o deslocamento de bens materiais e imateriais.

A mobilidade é, sem dúvida, um dos fundamentos da existência humana. Ela está na origem da organização dos grupos e sempre se constituiu em um domínio estratégico. $\mathrm{Na}$ atualidade o papel da mobilidade se acentua. $\mathrm{O}$ número de objetos materiais e imateriais em movimento cresce desde que a sociedade industrial modificou radicalmente as condições de velocidade e de deslocamento. Chegando mesmo a quase instantaneidade de deslocamento quando se trata de bens imateriais.

O deslocamento de bens imateriais (capitais, informações, imagens, ordens, dados) é uma das faces da mobilidade e um dos elementos da organização espacial. Mesmo considerando sua "virtualidade" e quase instantaneidade, trata-se de um potente elemento espacial, portanto nos permite discuti-lo a partir do lugar. Essa é justamente a posição que sustentaremos neste texto: o lugar é incontornável em se tratando de análise geográfica. A despeito da velocidade precisamos lembrar que as redes ou as redes de redes são as bases materiais que asseguram a mobilidade de todos os bens. Esse dado não nos autoriza a negligenciar o lugar. Quando falamos de redes temos necessariamente que nos referir a nós, a 
ligação entre lugares. Quando falamos da transferência de dados, falamos do albergamento dos mesmos. Estar nas nuvens é apenas uma metáfora. O desafio aqui, não é a invenção de novas categorias, o desafio é como discutir hoje o lugar. A velocidade contemporânea dá ao lugar outra substantivação. E nos parece que a pergunta que os geógrafos têm que se fazer é: como discutimos o lugar hoje? Cabe lembrar que essa discussão passa pela discussão da noção de escala, da qual não trataremos.

Ao contrário do que se possa imaginar, quanto mais velocidade, mais o espaço tem importância. Pois o espaço não se reduz a uma distância a ser percorrida. A velocidade, assim como o tempo, é um dado dos objetos, portanto um dado geografizado, empiricizado. "O tempo empírico existe apenas pelos lugares, permitindo a transformação de um tempo geral o tempo do mundo - em um tempo particular" (SANTOS, 1983, p. 1078). Esse tempo diz respeito ao tempo de cada pessoa, de cada empresa, de cada instituição e se realiza em função das condições técnicas e organizacionais de cada lugar. "É, pois o lugar que determina o tempo e não o tempo que determina o lugar" (SANTOS, 1983, p. 1078). Essa possibilidade (porque não é para todos) real da hipermobilidade da sociedade contemporânea se efetiva em função da diferenciação dos lugares, que são a fonte de todo deslocamento. A diferenciação dos lugares se define pelas densidades técnica, informacional e comunicacional (SANTOS, 2006, p. 257-258).

Como anunciamos desde o início, a mobilidade implica em circulação e comunicação. Faremos a partir de agora uma diferenciação entre circulação e comunicação apenas para tornar a explicação mais compreensiva. Entendemos que todo deslocamento implica em circulação-comunicação.

De maneira geral considera-se circulação o deslocamento de bens materiais e de pessoas (circuito espacial produtivo) e comunicação os fluxos de informações (círculos de cooperação). O que coloca os primeiros mais relacionados às redes de transportes e o segundo às redes de telecomunicações. Essa separação não deve ser rígida, pois tanto objetos como pessoas portam informações. Lembramos que além de falarmos de circulação e comunicação, ao tratarmos de circuito espacial produtivo, devemos nos reportar também à logística. Ver texto de Castillo e Frederico nesta mesma coletânea.

A circulação é a base para o funcionamento do circuito produtivo, é ela que permite as trocas e transferências, que dinamiza os processos e possibilita as interações entre os lugares nos autorizando a falar em circuito espacial. No entanto a condição necessária para todo esse 
processo é espacial. "Para que determinadas ações se produzam, é necessário que um certo arranjo físico-espacial seja concomitantemente produzido" (GOMES, 1997, p. 37). Esse arranjo físico-espacial é a configuração territorial, é o conjunto de objetos geográficos. Esse arranjo, essa configuração participa da hierarquia entre os lugares e configura diferenciações espaciais, daí a importância do lugar para a análise.

Grosso modo quando falamos em circulação devemos considerar pelo menos três aspectos articulados: a ligação entre os lugares, os modos de deslocamento e a natureza dos elementos. A circulação permite o funcionamento de um sistema de troca entre pessoas e entre lugares - portos, aeroportos, cidades, regiões, países (ligação). Essas trocas se efetivam através de rodovias, ferrovias, hidrovias, aerovias (deslocamento). A natureza dos elementos diz respeito às características do que é transportado. Todo esse conjunto implica em rede de transporte. Lembramos que toda rede é por natureza possibilidade de ligações, mas também é fechamento, restrição. Isso requer da análise territorial elementos para além das redes.

Comunicação é fluxo de informação. Antes de tudo, esse par (comunicaçãoinformação) é constituído por um conjunto de objetos concretos e está intimamente ligado à produção stricto sensu contribuindo para especialização dos lugares e induzindo a troca. Esse fato requer análise espacial. O mito da abolição das distâncias gerou a falta de interesse, principalmente dos geógrafos, das implicações espaciais das TICs (tecnologia de informação e comunicação). Vale a pena lembrar que "um dos problemas fundamentais inerentes a qualquer estudo sistemático da organização do espaço é determinar: por que cada coisa está situada num determinado lugar em vez de em outro qualquer" (SANTOS, 2003, p. 56). Neste sentido um estudo sobre circuito espacial produtivo e os círculos de cooperação deve indagar sobre qual é o impacto das redes de telecomunicação sobre a concentração de pessoas e de atividades, sobre a circulação e sobre a localização das empresas e da mão-de-obra. Qual o seu impacto nos lugares?

Feitas essas breves considerações nosso intuito, a partir desse ponto, é mostrar a importância do lugar na análise sobre circuitos espaciais produtivos. Santos (2008a, p. 53) chama a atenção para o seguinte fato: "quanto mais os lugares se mundializam, mais se tornam singulares e específicos, isto é, únicos". Se isso é verdade o elemento que dá singularidade ao circuito é o lugar. É no lugar que se dá a combinação única entre produção, circulação, troca e consumo. Cabendo ao pesquisador fazer uma análise situacional entendendo a localização não como um ponto, mas como um recurso. A configuração 
territorial dá aos lugares especificidades, criando diferenciações espaciais e dotando os lugares de aptidões que permitem a instalação, ou não, de determinadas atividades. Essa dotação, que dá característica própria a cada lugar, é o que Milton Santos vai chamar de Lei do Lugar.

Os circuitos produtivos se estruturam sempre em função de uma dada atividade que envolve a produção propriamente dita, a circulação, a distribuição e o consumo. "Só a produção propriamente dita tem relação direta com o lugar e dele adquire uma parcela das condições de sua realização" (SANTOS, 2008b, p. 13). A produção propriamente dita é a face mais evidente de todo o processo, é ela que lhe dá corporeidade e significação. Essa corporeidade produz uma topologia que permite a análise da distribuição das áreas de produção e dos lugares de produção.

Ao fazer a análise do lugar o pesquisador não deve se esquecer de levar em consideração outra categoria importante qual seja aquela de evento, "porque permite unir o mundo ao lugar; a História que se faz e a História já feita; o futuro e o passado que aparece como presente" (SANTOS, 1999, p. 15). A combinação entre evento e lugar cria o novo, o único. O mundo é um feixe de variáveis que contém todas as possibilidades, o evento é o portador de algumas dessas possibilidades. A realização dessas possibilidades somente é possível no lugar. É o lugar que dá existência ao evento enquanto possibilidade, é o lugar que revela o evento e o torna único. "Cada lugar é uma combinação única qualitativa e quantitativamente de vetores" (SANTOS, 2006, p. 151). Os lugares podem ter conteúdos parecidos, mas nunca idênticos. Podemos mesmo dizer que o lugar se define pela combinação única da realização e corporificação de algumas das possibilidades que existem no mundo apenas como possibilidades: que são os eventos. O lugar é também "funcionalização do mundo e é por ele (lugar) que o mundo é percebido empiricamente" (SANTOS, 2005, p. 158). É importante frisar que cada variável, que compõe um determinado evento, "é inteiramente desprovida de significação fora do sistema ao qual pertence" (SANTOS, 1990, p. 254) e do lugar no qual se instala.

A empiricização do mundo permite falar em área de ocorrência de determinado evento que se realiza no lugar e se superpõem à área de ocorrência de outros eventos. Cada evento apresenta uma escala de origem e uma escala de realização. A primeira se refere às forças operantes que produzem os eventos, a segunda é a escala do fenômeno que se remete à área de ocorrência e é dada pela extensão do evento. Os eventos são individuais, mas não isolados, 
eles fazem-se numa combinação interdependente, formando uma trama complexa, compreensível a partir da totalidade, que requer se levar em consideração materialidade e sentido.

Entender essa totalidade requer levar em consideração as noções de verticalidade e de horizontalidade, de materialidade e de sentido. As horizontalidades estão vinculadas ao lugar e dizem respeito ao local de produção e de consumo, aos espaços justapostos, constituídos de pontos contínuos, espaço da racionalidade e da contrarracionalidade; o que faz do lugar o palco das tensões entre o mundo e o cotidiano. As verticalidades relacionem-se com o global, ligam pontos remotos, são veículos de uma racionalidade exterior e estranha ao lugar, tende a impor a lógica da "modernidade", dizem respeito ao interesse de poucos que tende a regular a vida cotidiana. As tensões entre verticalidades e horizontalidades dão aos circuitos produtivos uma “forma desagregada, embora não desarticulada" (SANTOS, 2008b, p. 14).

Cabe ao pesquisador imbuído do raciocínio geográfico (aquele que tem em sua base a ordem espacial de objetos e ações e a trama relacional das localizações e lugares) situar o conjunto de variáveis que compõe o circuito produtivo estudado, estabelecendo entre elas suas ligações e nexos. São nestas ligações e em seus nexos que consiste a explicação geográfica. Lembrando que "a escolha das variáveis não pode ser, todavia, aleatória, mas deve levar em conta o fenômeno estudado e sua significação em um dado momento, de modo que as instâncias econômica, institucional, cultural e espacial sejam adequadamente consideradas" (SANTOS, 2008b, p. 14). O resultado dessa análise nos permite falar de uso do território e de lugar. O conjunto de variáveis que viabiliza uma determinada produção, como por exemplo, a produção de cana, implica na noção de uso do território. A combinação específica para esse uso é o lugar. Grosso modo poderíamos dizer que a produção de cana é o uso do território e a especificidade de cada produção é dada pelo lugar. O Território é uso, o Lugar é a combinação para esse uso.

O lugar dá diversidade às variáveis, "cada elemento do espaço tem valor diferente segundo o lugar em que se encontra" (SANTOS, 2008b, p. 21). Uma usina de açúcar montada no Rio Grande do Norte e outra montada em Pernambuco pela mesma firma, ao mesmo tempo e com as mesmas condições técnicas, darão resultados diferentes, mesmo considerando igual quantidade de produção de açúcar. Essa diferença somente pode ser explicada pelo lugar.

Sociedade e Território - Natal. Vol. 28, N. 1, p. 193 -199. Jan./Jun. de 2016 


\section{REFERÊNCIAS}

CASTILLO, Ricardo; FREDERICO, Samuel. Espaço geográfico, produção e movimento: uma reflexão sobre o conceito de circuito espacial produtivo. Sociedade \& Natureza, Uberlândia, v. 3, n. 22, p. 461-474, dez. 2010. Disponível em:

<http://www.seer.ufu.br/index.php/sociedadenatureza/article/view/11336>.

GOMES, Paulo C. da C.. Geografia fin-de siècle: O discurso sobre a ordem espacial do mundo e o fim das ilusões. In. CASTRO, I; GOMES, P.C.C; CORRÊA, R.L.. Explorações Geográficas. Rio de Janeiro: Bertrand Brasil, 1997.

SANTOS, Milton. Posface: Les nouveaux mondes de la géographie. In: BAILLY, A.; FERRAS, R.; PUMAIN, D.. Encyclopédie de Géographie. Paris: Economica, 1983.

. Por uma Geografia Nova. 3 ed. São Paulo: Edusp, 1990.

. O território e o saber local: algumas categorias de análise. In: Cadernos do IPPUR, Rio de Janeiro, 1999, Ano XIII, n. 2, p.15-26.

Economia Espacial. 2. ed. São Paulo: Edusp, 2003.

Da totalidade ao lugar. São Paulo: Edusp, 2005.

Natureza do Espaço. 4. ed. São Paulo: Edusp, 2006.

. Metamorfose do Espaço Habitado. 6. ed. São Paulo: Edusp, 2008(a).

Espaço e Método. 5. ed. São Paulo: Edusp, 2008(b).

Recebido em Março de 2016

Aprovado em Maio de 2016

Publicado em Junho de 2016

Sociedade e Território - Natal. Vol. 28, N. 1, p. 193 -199. Jan./Jun. de 2016 